\title{
Controllability of Complex Power Networks
}

\author{
Guohua Zhang ${ }^{1}$, Zhen $\mathrm{Li}^{1}$ \& Qiaoli Zhang ${ }^{1}$ \\ ${ }^{1}$ Hunan University of Technology, China \\ Correspondence: Guohua Zhang, Hunan University of Technology, Zhuzhou, Hunan, 412000, China. E-mail: \\ 9884188@qq.com
}

Received: January 30, 2018 Accepted: March 1, 2018 Online Published: March 28, 2018

doi:10.5539/nct.v3n1p1

URL: https://doi.org/10.5539/nct.v3n1p1

\begin{abstract}
With the progress of time, the power network has been the basis of economic development. However, people have little knowledge of the controllability of the power network. This article will study eight power networks and compare the controllability of the power network in many aspects.
\end{abstract}

Keywords: power network, controllable, command

\section{Introduction}

Power network supports the development of modern society, almost all industrial and life are highly dependent on electricity. China's power network covers an area of about $88 \%$ of the land area. Power transmission over an extremely long distance has caused the analysis of the dynamic behavior of power transmission in the network is rather complicated. The traditional method has shown its limitations.

Last few years, professional researchers began to study from the complex power network, the main study of the topology analysis, the robustness of the power network and attack vulnerabilities, power cascades and other cascading failure mechanism. However, few studies have connected the controllability of the network. In this paper, we use the controllability theory of the network to analyze the controllability of the network, the research objects include four node systems of IEEE standard test system, node system of North-East China (NEC) grid and node system of Middle China (MC), NEC and MC will adopt the connections and nodes above $220 \mathrm{kv}$ for modeling. Firstly, the controllability of the eight-power network is studied and compared with the controllability of ER stochastic networks, WS small world networks, NW small world networks, BA scale-free networks, configuration model (CM) After comparing, the influence of the main structural characteristics of power network on the controllability is also studied.

\section{Methods and models}

Use controllability theory to research the grid, how to solve the controllability theory (Figure 1).

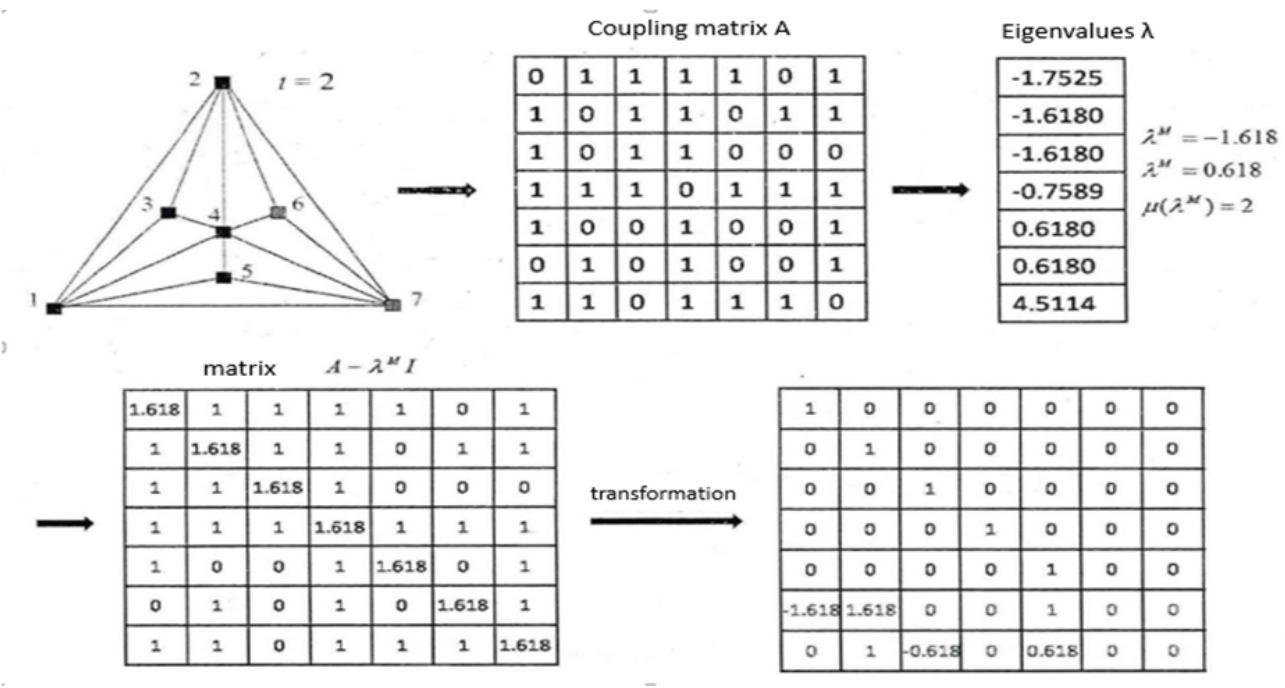

Figure 1. Network controllable node calculation 
Network configuration model $(\mathrm{CM})^{[1]}$ is an extension of the random network model ER, and ER model except that the model may be distributed $\mathrm{P}(\mathrm{k})$ according to the degree of power network generates a random, construct algorithm 2.1.

Algorithm 2.1:

Input: Degree distribution $\mathrm{P}(\mathrm{k})$

Output: A network having a random distribution of $\mathrm{P}(\mathrm{k})$ of

1). Generate a degree sequence of length $\mathrm{N}\left\{\mathrm{k} 1, \mathrm{k} 2, \mathrm{k} 3 \ldots, \mathrm{k}_{\mathrm{N}}\right\}$ according to the degree distribution $\mathrm{P}(\mathrm{k})$, representing degrees of $\mathrm{N}$ nodes of the network;

2). Select two nodes 1 and $\mathrm{j}\left(\mathrm{k}_{\mathrm{i}}, \mathrm{k}_{\mathrm{j}}>0\right)$ randomly from the network, and subtract 1 from the corresponding degree values $\mathrm{k}_{\mathrm{i}}$ and $\mathrm{k}_{\mathrm{j}}$, respectively;

3). Repeat step 2 until all nodes in the network have a value of 0 ; return to the resulting network.

Network configuration model has the following mathematical properties:

(1). The probability $P_{i j}$ of edge connection exists between any two nodes $i, j$ in the network. If two nodes are connected according to the random matching algorithm (Algorithm 2.1), one branch on the "Stump" corresponding to node $\mathrm{i}$ is connected to node $\mathrm{j}$ with a probability of $\mathrm{k}_{\mathrm{j}} /(2 \mathrm{~L}-1)$, while the node $\mathrm{i}$ itself has $\mathrm{k}_{\mathrm{i}}$ branches, so the probability that the node $\mathrm{i}, \mathrm{j}$ has a connection $\mathrm{P}_{\mathrm{ij}}$ is

$$
\mathrm{p}_{\mathrm{ij}}=\frac{\mathrm{k}_{\mathrm{i}} \mathrm{k}_{\mathrm{j}}}{2 \mathrm{~L}-1} \approx \frac{\mathrm{k}_{\mathrm{i}} \mathrm{k}_{\mathrm{j}}}{2 L}
$$

(2).The above formula when the number of network edge L is sufficiently large, the second equality holds. Equation (2.1) clearly shows that the greater the degree of nodes i, j, the greater the probability of their connection in the configuration network model. In addition, other important indicators of network configuration model also includes the number of edges parallel to the desired network

$$
E(\text { pallel }- \text { edges })=\frac{1}{2}\left[\frac{<k^{2}>-<k>}{<k>}\right]^{2}
$$

(3).The number of self-loop network expectations

$$
E(\text { self }- \text { loops })=\frac{<k^{2}>-<k>}{2<k>}
$$

(4). Network aggregation coefficient

$$
C=\frac{1}{N} \frac{\left(<k^{2}>-<k>\right)^{2}}{<k>^{3}}
$$

\section{Numerical simulation results}

Six power network IEEE paper: 30,57, 118, 145, 162, 300, NEC 127 and MC 302 node grid. For comparison, the same scale WS small-world network, ER stochastic network, CM configuration model network and BA scale-free network are set up. The CM configuration model network has the same degree distribution as the power network.

The main characteristics of the electricity network topology including nodes $\mathrm{N}$, the number of edges L, the average degree of $\langle\mathrm{k}\rangle$, clustering coefficient $\mathrm{C}$, the diameter D and the average path length APL. As shown in Table 1: 
Table 1.

\begin{tabular}{|c|c|c|c|c|c|c|}
\hline Network & $\mathbf{N}$ & $\mathbf{L}$ & $<\mathbf{k}>$ & $\mathrm{C}$ & D & APL \\
\hline IEEE 30 & 30 & 41 & 2.733 & 0.261 & 6 & 3.306 \\
\hline IEEE 57 & 57 & 78 & 2.737 & 0.124 & 12 & 4.954 \\
\hline IEEE 118 & 118 & 179 & 3.034 & 0.175 & 14 & 6.309 \\
\hline IEEE 145 & 145 & 422 & 5.821 & 0.581 & 11 & 4.391 \\
\hline IEEE 162 & 162 & 280 & 3.457 & 0.106 & 12 & 5.657 \\
\hline IEEE 300 & 300 & 409 & 2.727 & 0.111 & 24 & 9.935 \\
\hline NEC 127 & 127 & 163 & 2.567 & 0.071 & 16 & 7.112 \\
\hline MC 302 & 302 & 396 & 2.623 & 0.167 & 33 & 12.908 \\
\hline WS 30 & 30 & 60 & 4.000 & 0.363 & 5 & 2.871 \\
\hline WS 57 & 57 & 114 & 4.000 & 0.253 & 7 & 3.365 \\
\hline WS 118 & 118 & 236 & 4.000 & 0.262 & 9 & 4.441 \\
\hline WS 145 & 145 & 290 & 4.000 & 0.387 & 11 & 5.562 \\
\hline WS 162 & 162 & 324 & 4.000 & 0.341 & 10 & 5.287 \\
\hline WS 300 & 300 & 600 & 4.000 & 0.251 & 10 & 5.306 \\
\hline WS 127 & 127 & 254 & 4.000 & 0.292 & 9 & 4.664 \\
\hline WS 302 & 302 & 604 & 4.000 & 0.286 & 11 & 5.573 \\
\hline ER 30 & 30 & 41 & 2.733 & 0.133 & 9 & 3.175 \\
\hline ER 57 & 57 & 78 & 2.737 & 0.028 & 12 & 4.479 \\
\hline ER 118 & 118 & 181 & 3.068 & 0.008 & 9 & 4.323 \\
\hline ER 145 & 145 & 412 & 5.683 & 0.0345 & 6 & 3.026 \\
\hline ER 162 & 162 & 283 & 3.494 & 0.0108 & INF & INF \\
\hline ER 300 & 300 & 406 & 2.707 & 0.003 & INF & INF \\
\hline ER 127 & 127 & 178 & 2.803 & 0.009 & 10 & 4.785 \\
\hline ER 302 & 302 & 393 & 2.603 & 0.008 & INF & INF \\
\hline CM 30 & 30 & 41 & 2.733 & 0.0222 & 9 & 3.526 \\
\hline CM 57 & 57 & 78 & 2.737 & 0.045 & 10 & 4.135 \\
\hline CM 118 & 118 & 179 & 3.034 & 0.209 & 10 & 4.556 \\
\hline CM 145 & 145 & 422 & 5.821 & 0.0956 & 7 & 3.081 \\
\hline CM 162 & 162 & 280 & 3.457 & 0.0155 & 9 & 4.312 \\
\hline CM 300 & 300 & 409 & 2.727 & 0.0095 & 13 & 5.969 \\
\hline CM 127 & 127 & 163 & 2.567 & 0.0037 & 13 & 5.574 \\
\hline CM 302 & 302 & 396 & 2.623 & 0.0169 & 15 & 6.004 \\
\hline BA 30 & 30 & 56 & 3.733 & 0.172 & 5 & 2.506 \\
\hline BA 57 & 57 & 110 & 3.860 & 0.182 & 5 & 2.718 \\
\hline BA 118 & 118 & 232 & 3.932 & 0.152 & 5 & 2.929 \\
\hline BA 145 & 145 & 286 & 3.945 & 0.0966 & 5 & 3.1156 \\
\hline BA 162 & 162 & 320 & 3.951 & 0.0843 & 6 & 3.284 \\
\hline BA 300 & 300 & 596 & 3.973 & 0.076 & 7 & 3.602 \\
\hline BA 127 & 127 & 250 & 3.937 & 0.127 & 6 & 3.110 \\
\hline BA 302 & 302 & 600 & 3.974 & 0.056 & 7 & 3.507 \\
\hline
\end{tabular}


It can be seen from Table 1 that the small-world network contains most of the power grids. (1) WS small- world network path length and the average path length of the gap is small, with the characteristics of a small world; (2) their clustering coefficient is much higher than the corresponding ER random network, with high concentration characteristics.

Calculate the controllability of the power network $\mathrm{N}_{\mathrm{D}}$, Figure 2:

\begin{tabular}{|c|c|c|c|c|c|c|c|c|}
\hline & 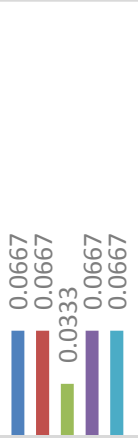 & 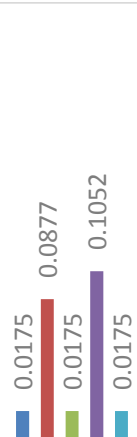 & 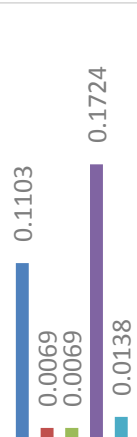 & 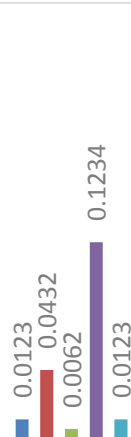 & 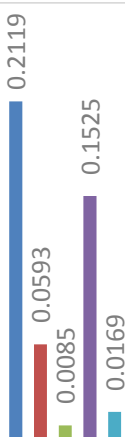 & 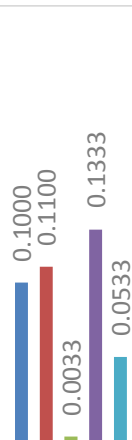 & 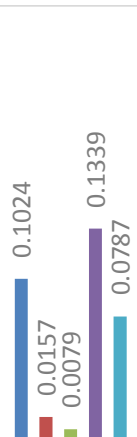 & 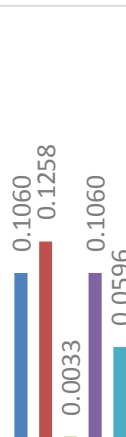 \\
\hline & IEEE30 & IEEE57 & IEEE145 & IEEE162 & IEEE118 & IEEE300 & NEC127 & MC302 \\
\hline N_D & 0.0667 & 0.0175 & 0.1103 & 0.0123 & 0.2119 & 0.1000 & 0.1024 & 0.1060 \\
\hline 口ER'sN_D & 0.0667 & 0.0877 & 0.0069 & 0.0432 & 0.0593 & 0.1100 & 0.0157 & 0.1258 \\
\hline WS'sN_D & 0.0333 & 0.0175 & 0.0069 & 0.0062 & 0.0085 & 0.0033 & 0.0079 & 0.0033 \\
\hline BA'sN_D & 0.0667 & 0.1052 & 0.1724 & 0.1234 & 0.1525 & 0.1333 & 0.1339 & 0.1060 \\
\hline - CM'sN_D & 0.0667 & 0.0175 & 0.0138 & 0.0123 & 0.0169 & 0.0533 & 0.0787 & 0.0596 \\
\hline
\end{tabular}

Figure 2. Controllability of Power Network $\mathrm{N}_{\mathrm{D}}$ Compared with the controllability of the same network

It can be seen from Figure 2 that the controllability $\mathrm{N}_{\mathrm{D}}$ of IEEE118, IEEE145, and NEC127 networks is much larger than that of the corresponding ER networks, indicating that ER networks are easier to control than them. The controllability of the power network $\mathrm{N}_{\mathrm{D}}$ is greater than or equal to the corresponding CM network, indicating that there are other factors that determine the network controllability in addition to the degree distribution, because the power network has the same degree distribution as the CM network, if the degree distribution is the only factor that determines the controllability of the network, the controllability $\mathrm{N}_{\mathrm{D}}$ of the power network and the controllability $\mathrm{N}_{\mathrm{D}}$ of the CM network should be exactly the same.There are practical difference between the two, the reason may be attributed to a large APL power network (Table 1), because the actual power network in the design needs to consider the geographical location of the power station and high-voltage line length and other physical constraints.

\section{Conclusion}

In this paper, the controllability of six kinds of IEEE power networks, Middle China power network and North-East China power network is studied by using controllability theory. It is found that the degree distribution of power network obeys power law distribution and exhibits scale-free characteristic. The controllable value $\mathrm{N}_{D}$ of electric network IEEE 118, IEEE 145 and Northeast China power network is much higher than that of corresponding ER random network, so it is more difficult to control; while other IEEE networks and China Central China power network are easier to control.

\section{References}

Liu, Y. Y., Slotine, J. J., \& Barabási, A. L. (2011). Controllability of complex networks. Nature, 473(7346), 167. https://doi.org/10.1038/nature10011

Rubinov, M., \& Sporns, O. (2010). Complex network measures of brain connectivity: uses and interpretations. Neuroimage, 52(3), 1059-1069. https://doi.org/10.1016/j.neuroimage.2009.10.003

Newman, M. E. (2003). The structure and function of complex networks. SIAM review, 45(2), $167-256$. https://doi.org/10.1137/S003614450342480

Wang, L. Z., Chen, Y. Z., Wang, W. X., \& Lai, Y. C. (2017). Physical controllability of complex networks. Scientific reports, 7, 40198. https://doi.org/10.1038/srep40198

Li, W., Wang, X., \& Zhu, Q. (2013). Topology analysis and clustering for localized network in SINA Weibo. 
Zhan, C., Chen, G., \& Yeung, L. F. (2010). On the distributions of Laplacian eigenvalues versus node degrees in complex networks. Physica A: Statistical Mechanics and its Applications, 389(8), 1779-1788. https://doi.org/10.1016/j.physa.2009.12.005

\section{Copyrights}

Copyright for this article is retained by the author(s), with first publication rights granted to the journal.

This is an open-access article distributed under the terms and conditions of the Creative Commons Attribution license (http://creativecommons.org/licenses/by/4.0/). 